\title{
Analysis and construction status of SG-II 5PW laser facility
}

\author{
Jianqiang Zhu ${ }^{1,2}$, Xinglong Xie ${ }^{1,2}$, Meizhi Sun ${ }^{1,2}$, Jun Kang ${ }^{1,2}$, Qingwei Yang ${ }^{1,2}$, Ailin Guo ${ }^{1,2}$, \\ Haidong Zhu ${ }^{1,2}$, Ping Zhu ${ }^{1,2}$, Qi Gao ${ }^{1,2}$, Xiao Liang ${ }^{1,2,3}$, Ziruo Cui ${ }^{1,2,3}$, Shunhua Yang ${ }^{1,2,3}$, \\ Cheng Zhang ${ }^{1,2,3}$, and Zunqi Lin ${ }^{1,2}$ \\ ${ }^{1}$ National Laboratory on High Power Laser and Physics, Shanghai 201800, China \\ ${ }^{2}$ Shanghai Institute of Optics and Fine Mechanics, Chinese Academy of Sciences, Shanghai 201800, China \\ ${ }^{3}$ University of Chinese Academy of Sciences, Beijing 100049, China \\ (Received 7 February 2018; revised 8 March 2018; accepted 19 March 2018)
}

\begin{abstract}
We present a recent progress of the SG-II 5PW facility, which designed a multi-petawatt ultrashort pulse laser based on optical parametric chirped-pulse amplification (OPCPA). The prior two optical parametric amplifiers have been accomplished and chirped pulses with an energy of $49.7 \mathrm{~J}$ and a full-width-at-half-maximum (FWHM) spectrum bandwidth of $85 \mathrm{~nm}$ have been achieved. In the PW-scale optical parametric amplification (OPA), with the pump pulse that has an energy of $118 \mathrm{~J}$ from the second harmonic generation of the SG-II 7th beam, the pump-to-signal conversion efficiency is up to $41.9 \%$, which to the best of our knowledge is the highest among all of the reported values for OPCPA systems. The compressed pulse is higher than $37 \mathrm{~J}$ in $21 \mathrm{fs}(1.76 \mathrm{PW})$, and the focal spot is $\sim 10 \mu \mathrm{m}$ after the closed-loop corrections by the adaptive optics. Limited by the repetition of the pump laser, the SG-II 5PW facility operates one shot per hour. It has successfully been employed for high energy physics experiments.
\end{abstract}

Keywords: conversion efficiency; multi-petawatt; optical parametric amplification; proton acceleration; ultrashort pulse

\section{Introduction}

Owing to the advances in laser technology and related material production over the past decades, many laboratories have started to build extreme light sources for the generation of pulses that have a large energy, narrow width and high peak power ${ }^{[1]}$. Such facilities would provide very strong fields, which are expected to provide breakthroughs in fundamental physics as well as related applications ${ }^{[2]}$. As engineering solutions, both optical parametric chirped-pulse amplification (OPCPA) using nonlinear crystals and chirped-pulse amplification (CPA) with Ti: sapphire and mixed Nd: glasses have been employed ${ }^{[1,3]}$. A high peak power, up to $\sim 5 \mathrm{PW}$, has been reported at the facility in Shanghai and Sichuan in China $^{[4,5]}$. In addition, a $4.2 \mathrm{PW}$ Ti: sapphire laser at $0.1 \mathrm{~Hz}$ has been achieved in Korea ${ }^{[6]}$. A facility named HighRepetition-Rate Advanced Petawatt Laser System (HAPLS) has been developed for the ELI-Beamlines by Lawrence Livermore National Laboratory (LLNL). The HAPLS takes

Correspondence to: X. Xie and M. Sun, 390 Qinghe Road, Jiading, Shanghai 201800, China. Email: xiex1329@mail.shcnc.ac.cn (X. Xie), eric913@siom.ac.cn (M. Sun) advantage of diode-pumped solid-state lasers (DPSSLs) as pump source and delivers compressed pulses with peak power of $0.5 \mathrm{PW}$ for each and at a repetition rate of $3.3 \mathrm{~Hz}^{[7]}$. OPCPA in noncollinear configuration is adopted primarily for the ultra-broadband gain bandwidth up to hundreds of nanometers, which support amplifications of few cycle pulses $^{[8,9]}$. OPCPA has other advantages such as the large gain in a single pass, small thermal loading, and high contrast ${ }^{[10]}$. Using various nonlinear crystals and schematic configurations, OPCPA can be applied for a wide range of central wavelengths, such as $808 \mathrm{~nm}^{[4-7]}, 910 \mathrm{~nm}^{[1,11,12]}$ and $1053 \mathrm{~nm}^{[3,13]}$. The disadvantages of OPCPA are mainly consisted of three aspects. First, the amplification stability is very sensitive with the phase-matching configurations; second, the amplification demands rigorously for high quality pump pulses both in spatial and temporal domains; third, there are few available nonlinear crystals of aperture large enough, especially for high energy amplifiers. In the high energy amplifiers, the reported conversion efficiency of multi-pass CPA is up to $49 \%$, while the value of the state-of-the-art optical parametric amplification (OPA) keeps lower than $40 \%{ }^{[5]}$. The progresses of new amplification 
Table 1. The output capability and features of SG series laser facilities.

\begin{tabular}{|c|c|c|}
\hline Facility & Output capability & Features and current status \\
\hline SG-II facility & $\begin{array}{l}2.4 \mathrm{~kJ} / 1 \mathrm{~ns} / 3 \omega / 8 \mathrm{beams} / \Phi 20 \mathrm{~cm} \\
6 \mathrm{~kJ} / 1 \mathrm{~ns} / 1 \omega / 8 \mathrm{beams} / \Phi 20 \mathrm{~cm} \\
\text { several joules } / 100 \mathrm{ps} / 4 \omega / 1 \mathrm{beam} .\end{array}$ & $\begin{array}{l}\text { Precise and stable operation. } \\
\text { The } 7 \text { th beam is used as pump laser } \\
\text { for OPA-II of SG-II 5PW. }\end{array}$ \\
\hline SG-II 9th beam & $\begin{array}{l}5.13 \mathrm{~kJ} / 3.4 \mathrm{~ns} / 1 \omega / \Phi 32 \mathrm{~cm} \\
3 \mathrm{~kJ} / 3.4 \mathrm{~ns} / 3 \omega / \Phi 32 \mathrm{~cm} \text {; } \\
\text { probe laser: } 30 \mathrm{ps}, 80 \mathrm{ps}, 120 \mathrm{ps}-5 \mathrm{~ns} \\
\text { Eight nanosecond beams: }\end{array}$ & $\begin{array}{l}\text { Multi-functional laser system. } \\
\text { It will be used as pump laser for OPA- } \\
\text { III of SG-II 5PW. }\end{array}$ \\
\hline SG-II-UP facility & $\begin{array}{l}8.05 \mathrm{~kJ} / 5 \mathrm{~ns} / 1 \omega / \text { beam (maximal); } \\
40 \mathrm{~kJ} / 3.3 \mathrm{~ns} / 1 \omega / 8 \text { beams (routine); } \\
25 \mathrm{~kJ} / 3.3 \mathrm{~ns} / 3 \omega / 8 \text { beams (routine) } \\
\text { One picosecond petawatt beam: } \\
1 \mathrm{~kJ} /(1-10 \mathrm{ps}) /\left(10^{20} \mathrm{~W} / \mathrm{cm}^{2}\right) / \Phi 32 \mathrm{~cm} \text {. } \\
\text { One prototype beam: } \\
16 \mathrm{~kJ} / 5 \mathrm{~ns} / 1 \omega / 31 \mathrm{~cm} \times 31 \mathrm{~cm} \text {; } \\
17.5 \mathrm{~kJ} / 20 \mathrm{~ns} / 1 \omega / 31 \mathrm{~cm} \times 31 \mathrm{~cm} \text {. }\end{array}$ & $\begin{array}{l}\text { Good beam quality. } \\
\text { Fine controlling ability. } \\
\text { Large energy. } \\
\text { High fluence density. }\end{array}$ \\
\hline SG-II 5 PW facility & $\begin{array}{l}150 \mathrm{~J} / 30 \mathrm{fs} / 5 \mathrm{PW} / 808 \mathrm{~nm} \text { (designed); } \\
37 \mathrm{~J} / 21 \mathrm{fs} / 1.76 \mathrm{PW} \text { (prior two phases). }\end{array}$ & The OPA-III as the third phase is under development. \\
\hline
\end{tabular}

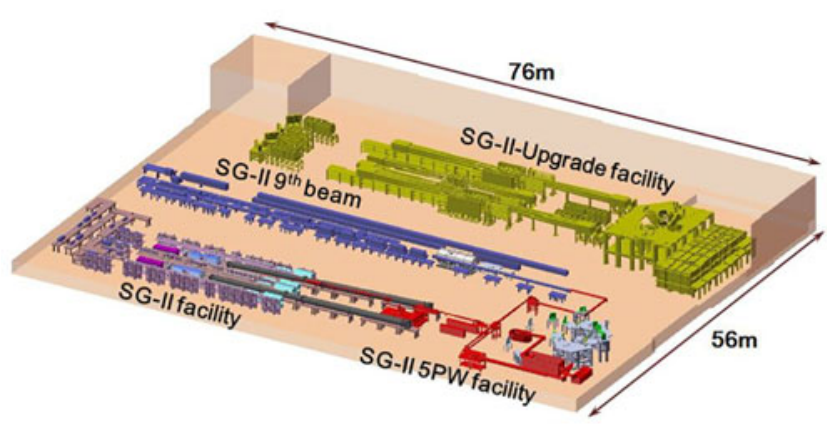

Figure 1. Layout of the SG series laser facilities.

technology and crystal growth have reduced the gap compared with CPA. An efficiency of $\sim 41 \%$ has been experimentally demonstrated using a quasi-parametric amplification (QPA) that employs a $\mathrm{Sm}^{3+}$-doped YCOB crystal ${ }^{[14]}$. Generally speaking, a higher conversion efficiency for the master optical parametric amplifier is still required.

\section{Architecture strategy}

In this report, we provide a detailed introduction on the design specifications and current performance of the Shen Guang-II 5PW (SG-II 5PW) laser facility at the National Laboratory on High Power Laser and Physics (NLHLP), Shanghai Institute of Optics and Fine Mechanics, Chinese Academy of Sciences (SIOM, CAS). NLHLP has studied solid-state laser technologies and engineering for half a century and has developed SG series laser drivers for the research on inertial confinement fusion (ICF) in China. As shown in Figure 1, the SG series covers a region of $76 \mathrm{~m} \times$ $56 \mathrm{~m}$ and currently consists of SG-II, SG-II 9th beam, SG-IIUpgrade (SG-II-UP) and SG-II 5PW laser facilities. There used to be another laser facility named SG-I which ex-served in 1995. All of the laser facilities of the SG series except for the SG-II 5PW are based on Nd: glasses that pumped by xenon lamps, and operate in single shot $\left(1-2 \mathrm{~h} \cdot \operatorname{shot}^{-1}\right)$. The SG-II facility is capable of delivering pulses of $6 \mathrm{~kJ}$ at $1053 \mathrm{~nm}(1 \omega)$ and $2.4 \mathrm{~kJ}$ at $351 \mathrm{~nm}(3 \omega)$ when the pulse duration is $1 \mathrm{~ns}$ with all of the eight laser beams, one of which can provide probe laser pulses of several joules in $100 \mathrm{ps}$ at $266 \mathrm{~nm}(4 \omega)$. The SG-II 9th beam is a multi-functional laser facility, and it can provide pulses of $5.13 \mathrm{~kJ}$ at $1 \omega$ and $3 \mathrm{~kJ}$ at $3 \omega$ in $3.4 \mathrm{~ns}$. In addition, it can provide probe lasers for physical experiments with tunable pulse bandwidths of $30 \mathrm{ps}, 80 \mathrm{ps}$ and $120 \mathrm{ps}-5 \mathrm{~ns}$. SG-II-UP facility consists of eight nanosecond pulse beams and one picosecond petawatt pulse beam. The eight nanosecond beams regularly operate at $40 \mathrm{~kJ} / 3.3 \mathrm{~ns} / 1 \omega$ and $25 \mathrm{~kJ} / 3.3 \mathrm{~ns} / 3 \omega$. The maximum $3 \omega$ fluence density achieved now is $5.5 \mathrm{~J} \cdot \mathrm{cm}^{-2}$ with the beam size of $310 \mathrm{~mm} \times 310 \mathrm{~mm}$. The picosecond petawatt beam can deliver pulses of $1 \mathrm{~kJ} / 10 \mathrm{ps}, 700 \mathrm{~J} / 3 \mathrm{ps}$ and $350 \mathrm{~J} / 1 \mathrm{ps}$ at $1 \omega$ after compression, similar to that obtained by the Omega EP at the University of Rochester ${ }^{[15]}$. In addition, for the studies on higher fluence density amplification, we have developed a prototype beam that is capable to operate at $16 \mathrm{~kJ} / 5 \mathrm{~ns} / 1 \omega$ and $17.5 \mathrm{~kJ} / 20 \mathrm{~ns} / 1 \omega$ with beam aperture $310 \mathrm{~mm} \times 310 \mathrm{~mm}$. The maximized fluence density is up to $18.2 \mathrm{~J} \cdot \mathrm{cm}^{-2}$ and such a value is at the same level of those highest in the world ${ }^{[16]}$. The output capability of SG series is summarized in Table 1. Therefore, the SG series are open and excellent integrated multi-functional laser platforms that have significance in various physics researches ${ }^{[17,18]}$. Based on the conditions above, SG-II 5PW is established as a part of the SG series laser platform to provide femtosecond multi-petawatt pulses for a multi-functional expansion. It has great potential applications for physics experiments in various operation modes, self-contained or combined with nanosecond kilojoules pulses from other laser beams and 


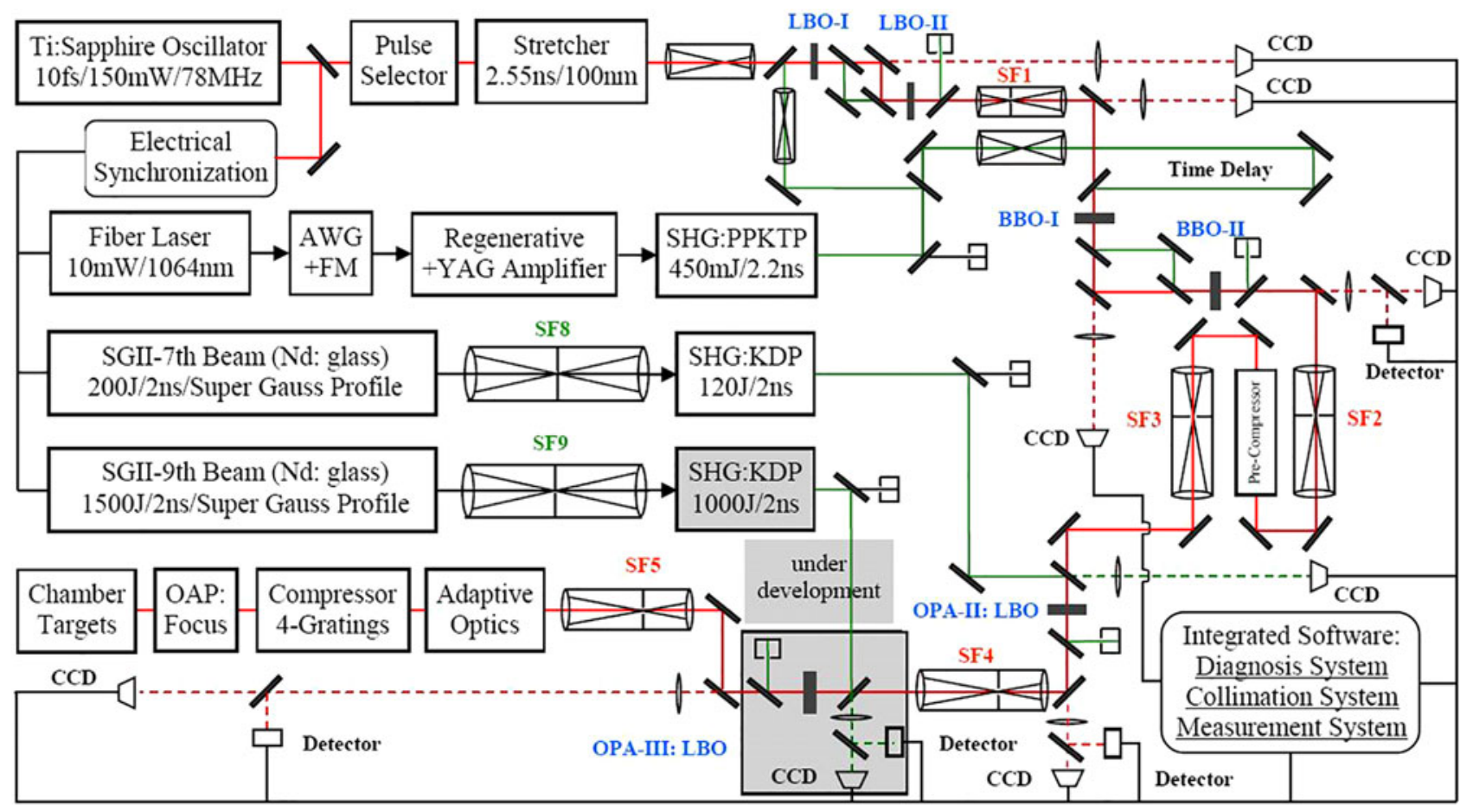

Figure 2. Schematic of the SG-II 5PW laser facility. AO: adaptive optics; HS: Hartmann sensor; DM: deformable mirror; OAP: off-axis parabolic mirror; AWG: arbitrary waveform generator; FM: frequency modulator.

facilities with a precise synchronization of $7.6 \mathrm{ps}$ root mean square (RMS) ${ }^{[19]}$.

The design of the SG-II 5PW facility is shown in Figure 2, and it relies on the implementation of a three-stage noncollinear OPCPA centered at $808 \mathrm{~nm}$. The shaded parts in the figure are under development. The designed specifications can be described as follows. All stages are expected to realize compressed pulses that have high power of different orders, $1-10 \mathrm{TW}$ at the first, $1 \mathrm{PW}$ at the second, and $5 \mathrm{PW}$ at the third stage. The second harmonic generated pulses from the existing laser based on Nd:YAG, SG-II 7th beam and SGII 9th beam are employed as pump sources corresponding to the three stages. For the main amplifier based on a largeaperture $150 \mathrm{~mm} \times 150 \mathrm{~mm}$ LBO crystal, a chirped pulse that has energy higher than $250 \mathrm{~J}$ and a bandwidth broader than $40 \mathrm{~nm}$ is aimed. The beam is expanded to dimensions of $290 \mathrm{~mm} \times 290 \mathrm{~mm}$ by spatial filter 5 (SF5) before being injected into the adaptive optics (AO) and compressor, which can deliver $150 \mathrm{~J} / 30 \mathrm{fs}$ pulses. In order to satisfy the demands of strong field experiments, the focused intensity is designed to $\sim 10^{21} \mathrm{~W} \cdot \mathrm{cm}^{-2}$ and the energy concentration is $50 \%$ in twice diffraction limitations (2DL). At the focal spot, pulse contrast of larger than $10^{8}$ is required. An integrated software and user-friendly interface have been developed including diagnosis, collimation and measurement systems. Real-time online data in all units, including the state of affairs, amplified pulse energy, spectrum, pulse waveform, near field and far field are automatically collected, processed and stored ${ }^{[20]}$.

\section{Sub-system design and performance}

\subsection{Front end}

The front end consists of an oscillator, pulse selector, stretcher, first stage OPCPA, pre-compressor, laser based on Nd:YAG for the OPA pump and attached spatial filters. The mode-locked Ti:sapphire oscillator operates at $78 \mathrm{MHz}$ and produces $150 \mathrm{~mW}$ seed pulses for both signal amplification chains and photoelectric clock signal of the whole system. The oscillator provides $\sim 2 \mathrm{~nJ}$ pulses at $808 \mathrm{~nm}$ that have a duration of 10 fs and FWHM spectrum bandwidth about $100 \mathrm{~nm}$. A Pockels cell as a pulse selector is attached to reduce the repetition rate of OPA incident to a single shot and it operates synchronously with the master amplifier in experiments.

A four-pass Öffner stretcher is employed and shown in Figure 3 (left). The sizes of elements used in the stretcher are large enough to reduce the effects of spectrum clipping which will result in degeneration of contrast ${ }^{[21]}$. The chirped-pulse width after stretcher is $2.55 \mathrm{~ns}$ with the chirp ratio $25.5 \mathrm{ps} / \mathrm{nm}$ and spectrum bandwidth of $\sim 100 \mathrm{~nm}$. The signal energy per pulse is approximately $0.2 \mathrm{~nJ}$ after the stretcher. 


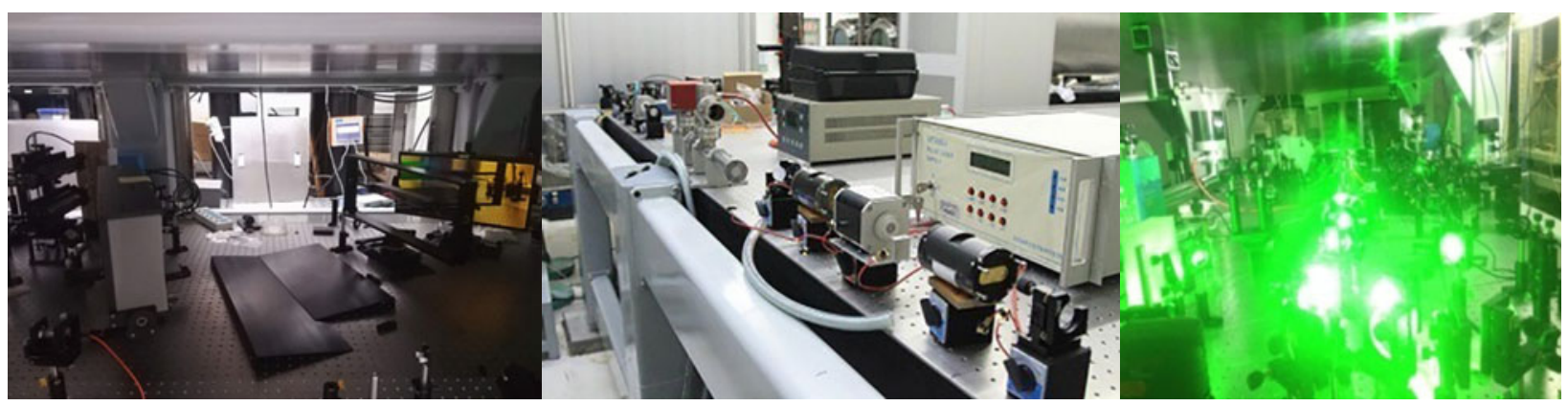

Figure 3. Four-pass Öffner stretcher (left), laser based on Nd:YAG (middle) and first stage OPCPA on operation (right).

The signal beam is shrunk to $\phi 5 \mathrm{~mm}$ in round and injected into the first stage OPCPA (OPA-I) that includes LBO and BBO crystals as preamplifiers. The laser based on Nd:YAG glass provides spatio-temporal super-Gauss profile pulses at $1064 \mathrm{~nm}$ at $1 \mathrm{~Hz}$ repetition rate (Figure 3 (middle)). And a second harmonic generator (SHG) employing PPKTP crystal is located after the laser to produce $532 \mathrm{~nm}$ monochromatic pump pulses of $450 \mathrm{~mJ}$ per pulse in $2.2 \mathrm{~ns}$ (solid blue line in Figure 4). Using a beam splitter, a $60 \mathrm{~mJ}$ pump pulse is conducted into the LBO-based amplifiers. An imagerelaying spatial filter is employed to reduce beam diameters and maintain a high quality near-field distribution of pump pulses at the position of OPA crystal. Critically phasematched type-I LBO 30-mm-long crystals $\left(\theta=90^{\circ}, \varphi=\right.$ $12.71^{\circ}$ ), are aligned successively in a configuration as shown in Figure 2 to maintain the parametric bandwidth $>60 \mathrm{~nm}$ and spatial overlap among signal, idler and pump pulses. The noncollinear angle $(\alpha)$ is set to $1.13^{\circ}$ in the crystal ${ }^{[22]}$. With the synchronization of 14 ps RMS, these amplifiers provide majority of the gain up to $10^{7}$ in the unsaturated regime and the signal energy per pulse exceeds $2 \mathrm{~mJ}$. With the waveform of approximate Gaussian profile (black line in Figure 5) after the stretcher, the amplified waveform and spectrum are represented by the blue lines in Figure 5 and Figure 6, respectively. The temporal waveforms of the pump pulses and chirped signal pulses are measured online by photodiodes and displayed by oscilloscope. The photodiodes and oscilloscope are commercial products, which have bandwidths sufficient for nanosecond pulses' measurements. The signal spectrum ranges from $765 \mathrm{~nm}$ to $833 \mathrm{~nm}$. The FWHM bandwidth of $60 \mathrm{~nm}$ is in good agreement with the calculated parametric bandwidth and sufficient for the lateral amplifiers $^{[23]}$.

The lens-based telescope SF1 then expands the signal beam to a diameter of $10 \mathrm{~mm}$ in order to match the pump beam diameter of $8.5 \mathrm{~mm}$. Two type-I phase-matched BBO crystals are aligned in a configuration with an internal noncollinear angle of $\sim 2.36^{\circ}$. The BBO crystals are $15 \mathrm{~mm}$ in length and phase-matched at $\theta=23.8^{\circ}$. By coupling with $390 \mathrm{~mJ}$ pump pulses (intensity of $\sim 300 \mathrm{MW} / \mathrm{cm}^{2}$, well below the damage threshold), the signal pulses are further

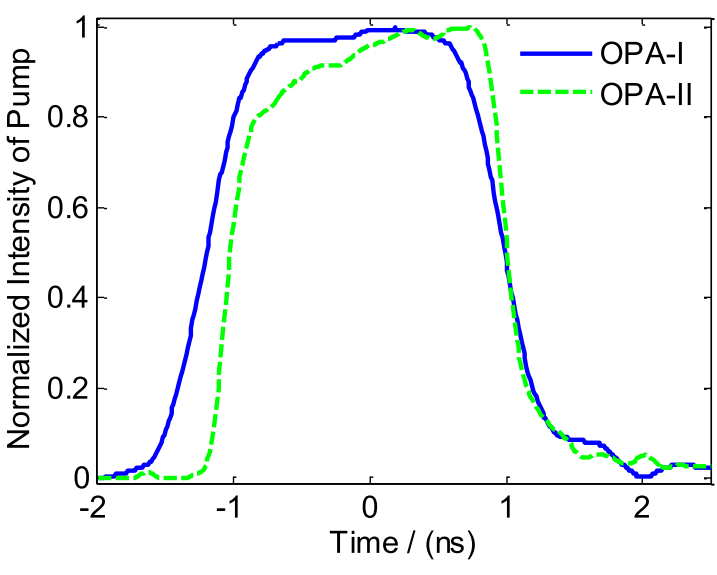

Figure 4. Waveforms of the pump pulses for OPA-I and OPA-II.

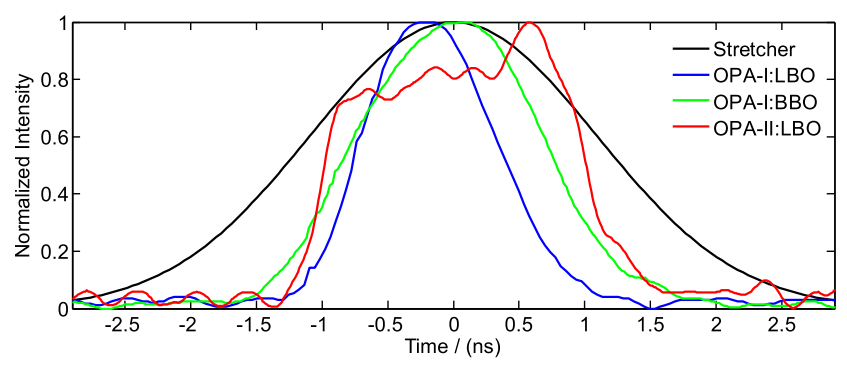

Figure 5. Waveforms of the chirped signal pulse along the current amplification chain.

boosted to $130 \mathrm{~mJ}$, and the total pump-to-signal conversion efficiency becomes $\sim 30 \%$. With the online measurement system, the normalized near-field distribution behind the SF3 and far-field distribution are presented in Figures 7(a) and 7(b), respectively. Numerical analysis shows that the circular energy is $84 \%$ in $2.9 \mathrm{DL}$ and $95 \%$ in 3.9 DL with focal lens $(f=750 \mathrm{~mm})$. The signal temporal bandwidth increases to $1.63 \mathrm{~ns}$ (green line in Figure 5), caused by the saturated amplification. On the other hand, by optimizing the synchronization, the FWHM spectrum centered at $\sim 815 \mathrm{~nm}$ covers the region of $784 \mathrm{~nm}$ to $846 \mathrm{~nm}$ (see green line in Figure 6). The OPA-I provides a total gain up to $6 \times 10^{8}$ 


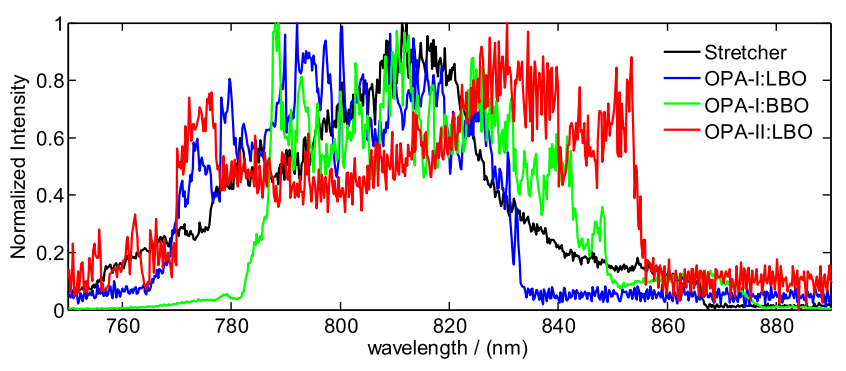

Figure 6. Signal pulse spectra for different amplification stages.

at a repetition rate of $1 \mathrm{~Hz}$ and achieves a hundreds of millijoules chirped pulse that is expected to be compressed for the several-terawatt experimental platform.

As a further explanation, both $\mathrm{LBO}$ and $\mathrm{BBO}$ in our opinion have gain bandwidth large enough to support the compressed duration of $30 \mathrm{fs}$. On the other hand, the gain bandwidth is larger than the soft spectrum clipping of the compressor. We choose LBO as the medium of high gain OPA stage, because LBO is of higher damage threshold and the pump beam diameter on LBO can be much smaller than that of BBO. In this way, the energy of the pump pulse is smaller for high gain stage so that more energy left from the pump laser can be provided for the lateral high energy BBObased OPA stages. In the future, we will update the $\mathrm{Nd}$ : YAG-based pump laser, and the LBO crystals are planned to be replaced by $\mathrm{BBO}$ crystals for a broader spectrum. All of the LBO and BBO crystals are cut with $1^{\circ}$ wedge angles at the rear faces and coated on the surfaces with $532 \mathrm{~nm}$ and $808 \mathrm{~nm}$ broadband antireflective films to suppress the parametric oscillation. The spatial filters between the stages, including SF1-SF5, are aligned with the pinholes to suppress the high-frequency modulations. Owing to the spatially dispersive characteristics, the optical parametric fluorescence (OPF) that generates in the amplification and transmits as high-order angular spectra can also be significantly suppressed by the pinholes in the spatial filters. The precompressor, located behind SF2, consists of two pairs of gold-coated diffraction gratings successively arranged ${ }^{[24]}$. The chirped ratio is $-4.2 \mathrm{ps} \cdot \mathrm{nm}^{-1}$, and the gratings are of 1740 groove $\cdot \mathrm{mm}^{-1}$ and sizes of approximately $40 \mathrm{~mm} \times$ $60 \mathrm{~mm}$ and $110 \mathrm{~mm} \times 110 \mathrm{~mm}$ with the incidence angle $56^{\circ}$. The pre-compressor is used to compensate the mismatch between the stretcher and master compressor. By a precise regulation, not only the shortest pulse width can be achieved, but also the third-order dispersion can be tuned to eliminate its effect on the contrast degeneration at the front edge of the compressed pulse. The optimal transmission efficiency of the pre-compressor of $\sim 75 \%$ is equal to that of the master compressor. So $90 \mathrm{~mJ}$ chirped pulses that have a diameter expanded to $\phi 85 \mathrm{~mm}$ by SF3, are injected into the second OPCPA stage (OPA-II).

\subsection{PW OPA-II}

The second OPA stage is designed to realize $1 \mathrm{PW}$ (compressed $30 \mathrm{~J} / 30 \mathrm{fs}$ ) with the SHG of the 7th beam of SG-II facility as the pump source (Figure 8). A precisely designed soft-edge aperture is used in the SG-II front end to modulate the fundamental pulse profile from a round spot into a square. By optimizing the pinholes size in the succeeding low-pass spatial filters in order to adjust to the soft-edged aperture, the beam quality is greatly improved. The beam size is restricted to $60 \mathrm{~mm} \times 60 \mathrm{~mm}$ after the Nd:glass amplifier that is capable to provide a $200 \mathrm{~J}$ pulse at $1053 \mathrm{~nm}^{[25,26]}$. A large-aperture 22-mm-thick KDP crystal is utilized as the second harmonic generator and the SHG conversion efficiency is approximately $70 \%$. The temporal waveform of the $\mathrm{SH}$ is represented by the dashed green line in Figure 4 and the spatial profile is presented in Figure 9. The FWHM bandwidth is $2 \mathrm{~ns}$, which is required to be slightly shorter
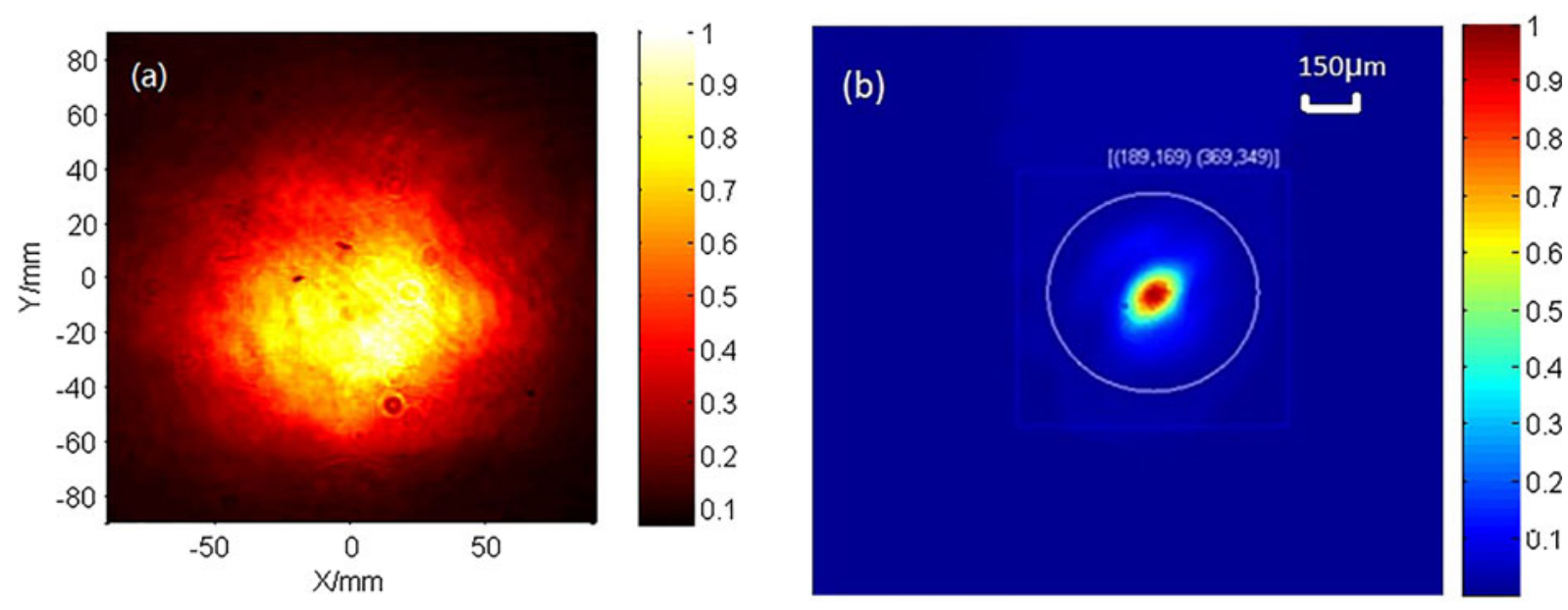

Figure 7. (a) Normalized near-field distribution and (b) far-field focal spot of OPA-I. 

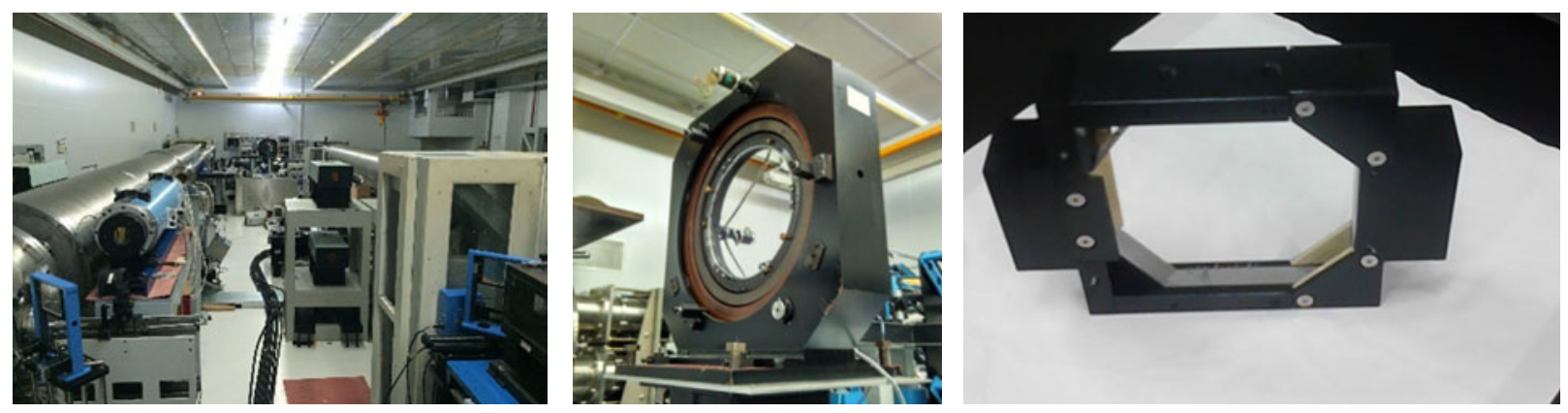

Figure 8. SG-II laser facility (left), a large-aperture KDP crystal (as a second harmonic generator (middle)), and a large-aperture LBO crystal in the second OPCPA stage (right).
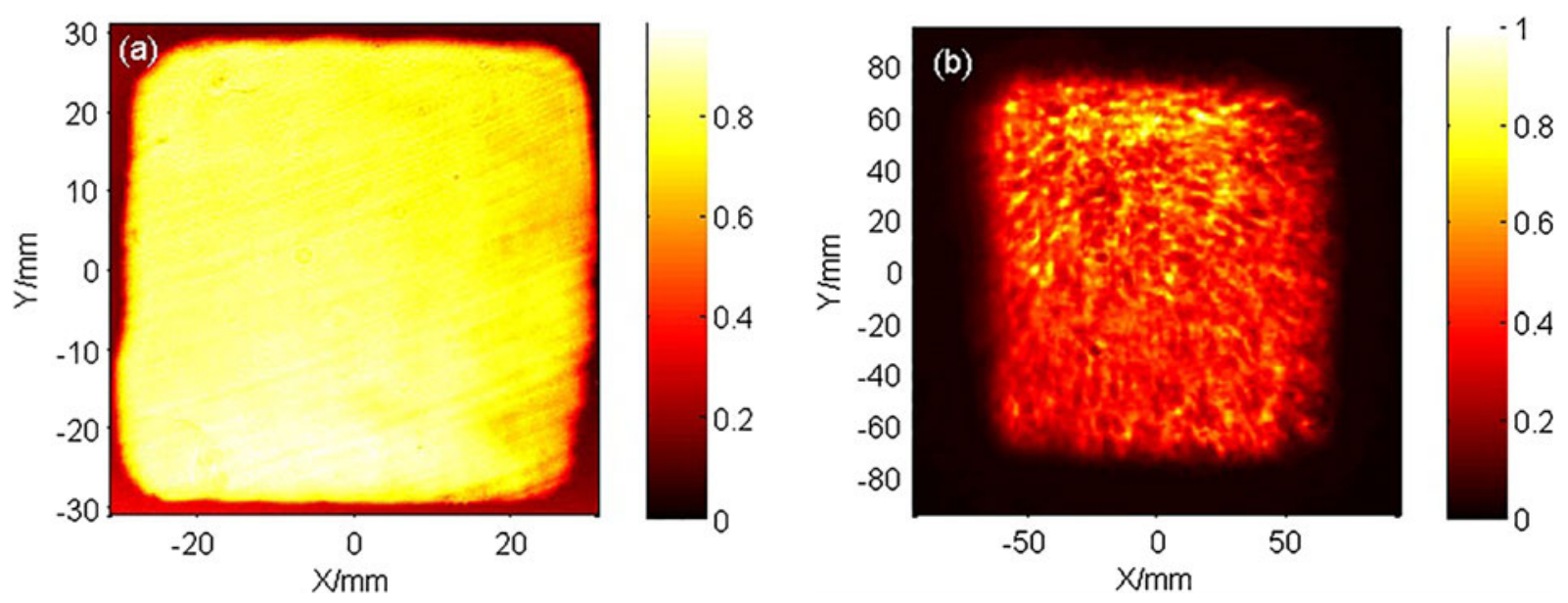

Figure 9. (a) Near-field distributions of the pump at location of LBO crystal and (b) signal pulse after the master compressor.

than that of the signal pulse determined by the phasematching bandwidth and chirped ratio. The fill factor (FF) and fluence beam contrast (FBC) are used to quantitatively describe the near-field distribution characteristics and they are defined in a fixed spatial region by formulas $\mathrm{FF}=\bar{I} / I_{\max }$ and $\mathrm{FBC}=\sqrt{1 / m n \sum_{i=1}^{m} \sum_{j=1}^{n}\left[\left(I_{i j}-\bar{I}\right) / \bar{I}\right]^{2}}$, in which $\bar{I}$ is the average intensity, $I_{\max }$ is the maximal intensity, $m$ and $n$ are the discrete dot numbers in the fixed region, and $I_{i j}$ is the measured intensity corresponding to the point $(i, j)$. A numerical analysis shows that the FF and FBC of pump pulses are 0.7546 and 0.26 , respectively.

A state-of-the-art OPA based on a 19 -mm-thick LBO is adopted in a type-I phase-matching noncollinear configuration in $X O Y$ principle plane. The matching angle is set to $\theta=90^{\circ}$ and $\varphi=13.85^{\circ}$ and the noncollinear angle is $1.25^{\circ}$ in the crystal ${ }^{[27]}$. In the latest experiment, the largest energy of the amplified chirped pulse up to $49.7 \mathrm{~J}$ was achieved with the pump pulse of $118.6 \mathrm{~J}$ in energy and $\sim 1.7 \mathrm{GW} \cdot \mathrm{cm}^{-2}$ in fluence intensity, and the gain reached a value of 550. The pump-to-signal conversion efficiency is $41.9 \%$, which to the best of our knowledge is the highest among the values reported for OPCPA facilities. The online measurement system provides the energy statistics of both signal and pump pulses for 13 shots in Figure 10. The mean values of amplified chirped-pulse energy and OPA conversion efficiency are $41.37 \mathrm{~J}$ and $37.8 \%$ with the pump pulse energy of $109 \mathrm{~J}$ on average. The RMS values of amplified chirped-pulse energy and OPA conversion efficiency are, respectively, $13.94 \%$ and $10.32 \%$ corresponding to the RMS value $7.76 \%$ of pump pulse energy. As shown by the red line in Figure 5, the signal pulse width increases to $1.92 \mathrm{~ns}$, caused by the amplification in the saturation region, which is defined as the crystal length region longer than that corresponding to the highest conversion efficiency. The spectrum represented by the red line in Figure 6 is greatly extended from $770 \mathrm{~nm}$ to $855 \mathrm{~nm}$, and the FWHM spectrum bandwidth is approximately $85 \mathrm{~nm}$. The spectrum is measured after the master compressor and shows sharp edges on both sides. The most probable reason is the spatial clipping in the compressor and the spectrum after the OPAII is going to be measured directly in future for comparison. The near-field distribution of the signal pulse is measured after the master compressor and shown in Figure 9(b).

The precise synchronization and critically phase-matched alignment are required for high conversion efficiency. For OPA-II of SG-II 5PW, the synchronization of 100 ps (RMS) is precisely enough. The mismatches of noncollinear angle 


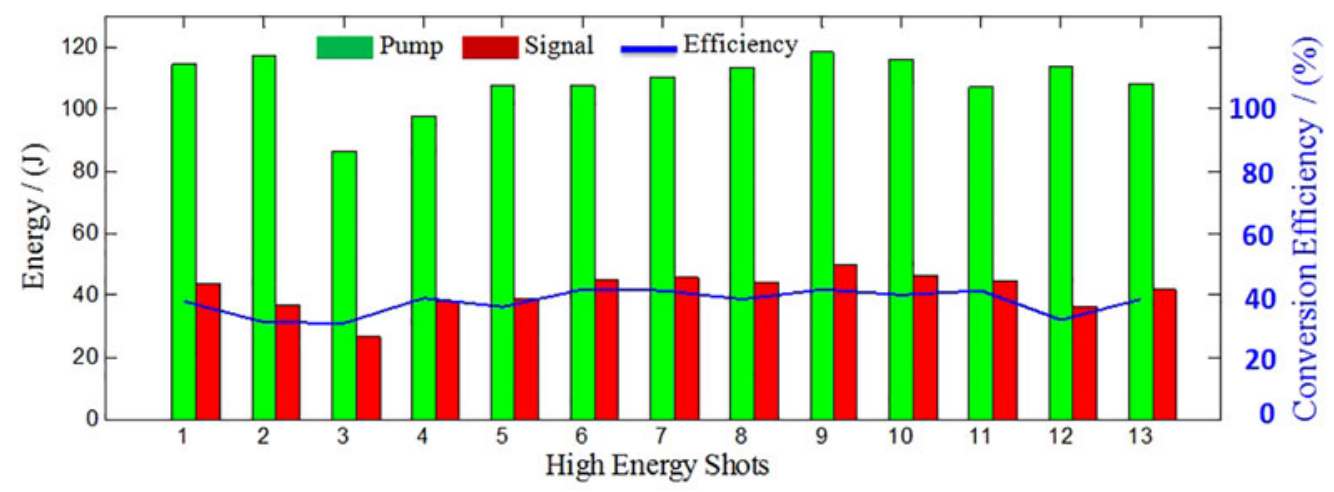

Figure 10. Statistics of the pump and signal pulses energy as well as the pump-to-signal conversion efficiency for all shots of the OPA-II.
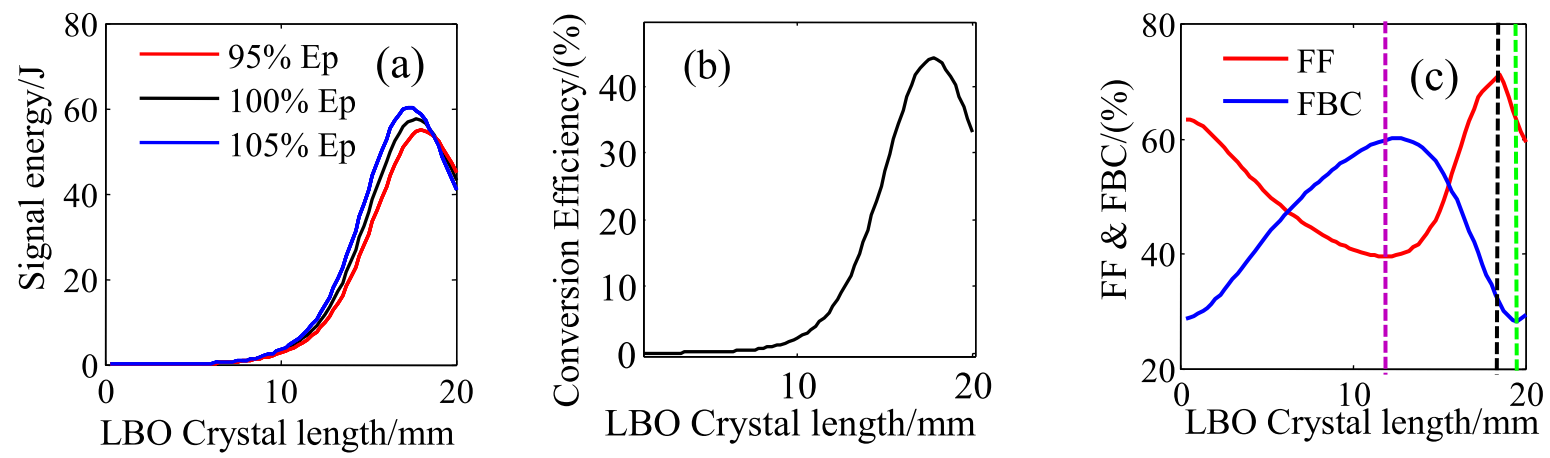

Figure 11. (a) Amplified signal energy fluctuation for various pumps, (b) conversion efficiency, and (c) FF (red line) and FBC (blue line) along the LBO length in the OPCPA-II; the dotted lines in (c) are borderlines of the four intervals.

and phase-matching angle must be, respectively, smaller than $0.01^{\circ}$ and $0.05^{\circ}$, which are determined by the acceptance angle in LBO crystal. The mismatch of noncollinear angle is determined by the monitoring precision on the beam pointing of the signal and pump beams, while the mismatch of phasematching angle is determined by the mechanical stability of the crystal clamp. The auto-collimation system is applied to adjust the beams pointing before shots with a correction precision for state recovery about $20 \mu \mathrm{rad}$, which is much smaller than the acceptance angle ( $\sim 1 \mathrm{mrad})$. In addition, the crystal length as well as the incident signal and pump pulses characteristics, including the energy, spatial-temporal profiles and wavefronts, should be taken into consideration. In order to improve the operation security, stability and conversion efficiency of the SG-II 5PW facility, the effects of the pump pulse near-field property and energy fluctuation on the OPCPA are numerically simulated along the crystal length, using parametric coupling wave equations ${ }^{[28]}$. The measured spatial-temporal profiles of the incident signal pulses are shown in Figures 5 and 7(a), and those of the pump pulse are shown in Figures 4 and 9(a). The numerical simulations are based on the measured data and indicate that the OPCPA stability is optimized at $18.75 \mathrm{~mm}$ when the pump energy floats $\pm 5 \%$ around $120 \mathrm{~J}$ (Figure $11(\mathrm{a})$ ). The conversion efficiency has a theoretical maximum of $44.5 \%$ at $17.75 \mathrm{~mm}$, while the value is $41.37 \%$ for the optimized stability crystal length of $18.75 \mathrm{~mm}$ (Figure 11(b)). More complex evolutions of the near-field FF and FBC of the signal pulses are presented in Figure 11(c). Owing to the coupling effects between three mixing waves, the maximum FF is achieved at $18.5 \mathrm{~mm}$, while the minimum FBC at $19.25 \mathrm{~mm}$. At the crystal length about $12.5 \mathrm{~mm}$, the FF is smallest and FBC is largest, which means the worst beam uniformity. Therefore, the crystal length can be divided into four regions: [0, $12.5 \mathrm{~mm}],[12.5 \mathrm{~mm}, 18.5 \mathrm{~mm}],[18.5 \mathrm{~mm}$, $19.25 \mathrm{~mm}]$ and $[19.25 \mathrm{~mm}, 20 \mathrm{~mm}]$. Taking into account the evolutions of the conversion efficiency and stability, it can be concluded that there is an optimal interval $[18.5 \mathrm{~mm}$, $19.25 \mathrm{~mm}$ ] of the nonlinear crystal length, in which a high beam quality, high conversion efficiency and high stability can be simultaneously achieved for fixed incidence pulses. The simulations and conclusions in Ref. [28] indicate that the pump wavefront phase distortions transfer into those of the signal when the walk-off direction is identical to that of the signal in the super-saturation region. In OPCPAII, we aligned the noncollinear configuration in order to make the walk-off direction identical to that of the idler to decrease the signal pulse wavefront degeneration caused by the pump wavefront distortion. The crystal length in the optimal interval $[18.5 \mathrm{~mm}, 19.25 \mathrm{~mm}$ ] is not far beyond 
Table 2. Comparison between LBO and DKDP calculations in OPA-III.

\begin{tabular}{llllllll}
\hline & $\begin{array}{l}\text { Crystal } \\
\text { length }(\mathrm{mm})\end{array}$ & $\begin{array}{l}\text { Signal energy } \\
(\mathrm{J})\end{array}$ & $\begin{array}{l}\text { Chirped } \\
\text { duration }(\mathrm{ns})\end{array}$ & $\begin{array}{l}\text { Spectrum } \\
\text { bandwidth (nm) }\end{array}$ & $\begin{array}{l}\text { Conversion } \\
\text { efficiency }\end{array}$ & $\begin{array}{l}\text { Compressed } \\
\text { duration (fs) }\end{array}$ & $\begin{array}{l}\text { Compressed } \\
\text { power (PW) }\end{array}$ \\
\hline DKDP & 35 & $\sim 250$ & 1.3 & 62 & $37 \%$ & $\sim 30$ & 5 \\
LBO & 13 & $\sim 250$ & 2 & 85 & $45 \%$ & 20 & $\sim 7$ \\
\hline
\end{tabular}
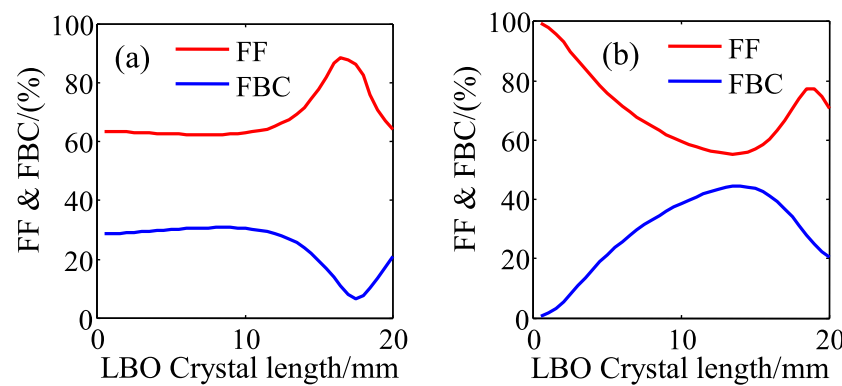

Figure 12. FF (red line) and FBC (blue line) for the OPCPA-II amplified signal as a function of the crystal length that correspond to the amplification (a) with the ideal spatial-temporal super-Gaussian pump pulse and actual signal pulse and (b) that with the ideal spatial-temporal super-Gaussian signal pulse and actual pump pulse, respectively.

the required crystal length of smaller than $17.75 \mathrm{~mm}$, at which the wavefront distortion of the amplified beam can be maintained in low level.

Additional simulations on FF and FBC are performed when the incident signal and pump pulses are set in ideal spatial-temporal super-Gaussian profiles so that we can quantitatively reveal which incident pulse affects the nearfield distribution performance of the OPCPA-II to a greater extent. As shown in Figure 12(a), using the ideal spatialtemporal super-Gaussian pump pulse and actual signal pulse, FF (red line) and FBC (blue line) for the OPCPA-II amplified signals are much better than those shown in Figure 11(c). In contrast, for the ideal spatial-temporal super-Gaussian signal pulse and actual pump pulse, both FF (red line) and FBC (blue line) at $19 \mathrm{~mm}$ in Figure 12(b) differ slightly from those shown in Figure 11(c). The results indicate that the pump pulse greatly affects the amplified beam uniformity. Enhancement of the SG-II 7th beam quality is a practical approach to improve the beam uniformity of OPCPA-II amplified signal pulses.

\subsection{Master amplifier under construction}

We aim to use the 9th beam of the SG-II facility for the pump of the master amplifier that can provide a compressed $5 \mathrm{PW}(150 \mathrm{~J} / 30 \mathrm{fs})$ pulse. The Nd:glass amplification chain in the 9 th beam has powerful abilities to achieve pulse energy larger than $5 \mathrm{~kJ}$ and a pulse width that is tunable in the range $1-3 \mathrm{~ns}$ at $1053 \mathrm{~nm}$ with an arbitrary waveform that can be controlled in both spatial and temporal domains ${ }^{[29]}$. The SHG with KDP crystal can provide sufficient pulse energy

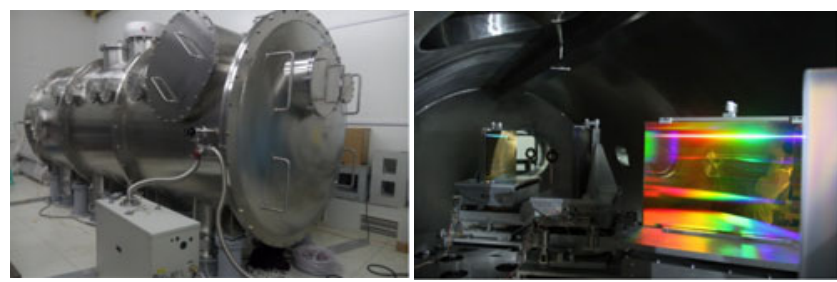

Figure 13. Compressor tank (left) and an inner image of the gold-coated gratings (right).

of $3 \mathrm{~kJ}$ at $526.5 \mathrm{~nm}$ that is significantly larger than the upper limitation value of $1 \mathrm{~kJ}$ required for the OPA-III. The image relay technique is used for both signal and pump optical path designs and the beam size of pump pulse is $145 \mathrm{~mm} \times$ $145 \mathrm{~mm}$ after the SF9. A large aperture of $150 \mathrm{~mm} \times$ $150 \mathrm{~mm} \times 13 \mathrm{~mm}$ LBO is required by numerical simulation for the high energy low-gain OPA, while the highest reported crystal size is $165 \mathrm{~mm} \times 120 \mathrm{~mm} \times 10 \mathrm{~mm}^{[4]}$. As a result, the DKDP of high level deuteration is an alternative choice, and it has been experimentally demonstrated on a desktop platform ${ }^{[30]}$. Combined with the numerical simulations based on the coupled wave equations, it can be concluded that a $35 \mathrm{~mm}$ DKDP crystal that has a deuteration level higher than $90 \%$ can be utilized in ultrashort high power laser systems with compressed pulses around $30 \mathrm{fs}^{[30,31]}$. Comparison between LBO and DKDP calculations is listed in Table 2.

\subsection{Master compressor and contrast measurement}

The master compressor contains four pieces of 1740 groove $\cdot \mathrm{mm}^{-1}$ gold-coated gratings that have a size of $360 \mathrm{~mm} \times 565 \mathrm{~mm}$. The gratings are aligned in a zigzag configuration, and placed in a tank that has a diameter of $1.7 \mathrm{~m}$ and a length of $4.9 \mathrm{~m}$. The guaranteed vacuum degree is $10^{-4}$ bar during operation (Figure 13). By a precise regulation, the compressor provides a chirped ratio of $-21.3 \mathrm{ps} / \mathrm{nm}$ and realizes output pulses that are temporally near the Fourier transform limitation. For the incident angle of $56^{\circ}$, the intensities on the surface are smaller than $0.16 \mathrm{~J} \cdot \mathrm{cm}^{-2}$ and $0.1 \mathrm{~J} \cdot \mathrm{cm}^{-2}$ for the first and last pieces of gratings, respectively, when all three amplifiers operate (smaller than half of the damage threshold).

The compressed pulse traces, measured by an autocorrelator, are shown in Figure $14^{[32]}$. The Gaussian profile 
Table 3. Design of multiple-stage spatial filters in SG-II 5PW system.

\begin{tabular}{|c|c|c|c|c|c|}
\hline & SF1 & SF2 & SF3 & SF4 & SF5 \\
\hline Size of incident beam (mm) & $\phi 2.5$ & $\phi 8.7$ & $\phi 20$ & $60 \times 60$ & $145 \times 145$ \\
\hline Focal length of incidence lens (mm) & 240 & 700 & 400 & 2480 & 2860 \\
\hline Focal length of output lens (mm) & 960 & 1930 & 1500 & 6000 & 5720 \\
\hline Size of output beam (mm) & $\phi 10$ & $\phi 24$ & $\phi 75$ & $145 \times 145$ & $290 \times 290$ \\
\hline Propagation time difference (fs) & 2 & 5 & 78 & 127 & 566 \\
\hline
\end{tabular}

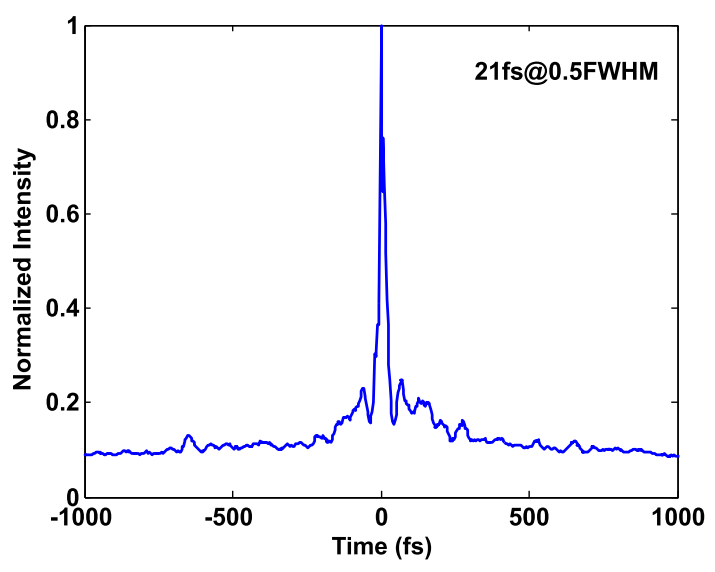

Figure 14. Compressed pulse duration with the whole beam diameter.

fitting shows that the FWHM pulse duration is $21 \mathrm{fs}$. What is more, the pulse traces indicate a substantially uncompressed pedestal ( $\sim 200 \mathrm{fs})$, which in our opinion mainly derives from the integral effect of chromatic aberrations. The chromatic aberrations are due to all of the lens-based spatial filters. In the future, an aberration pre-compensation unit will be installed in front of SF3 and numerical simulation indicates its effectiveness. Assuming that energy of the side pulse and uncompressed pedestal is ignorable, the compressed pulse energy is $37.2 \mathrm{~J}$ and the peak power is up to 1.76 PW. An appropriate contrast is highly demanded for physical experiments ${ }^{[33,34]}$. The contrast in the nanosecond temporal windows is measured by the photoelectric tube and oscilloscope, and it has been confirmed experimentally higher than that in the picosecond temporal windows. Therefore, in ultrashort pulse experiment, it is usually focused on the pulse contrast of the $100 \mathrm{ps}$ range. We measured the contrast by a third-order cross-correlator (Sequoia), as shown in Figure $15^{[35]}$. The contrast value due to the temporal pedestal at $20 \mathrm{ps}$ before the peak pulse is better than $10^{-6}$. It is featured that both pulse width and contrast are measured with the whole beam diameter by shrinking the beam from $290 \mathrm{~mm} \times 290 \mathrm{~mm}$ to $5 \mathrm{~mm} \times 5 \mathrm{~mm}$. These measurements with the whole beam diameter in large-aperture ultrashort laser facilities are reported for the first time, to the best of our knowledge ${ }^{[1,4-6,36]}$.

Next we analyze the temporal contrast in different time regions. Scattering in grating based stretchers has been

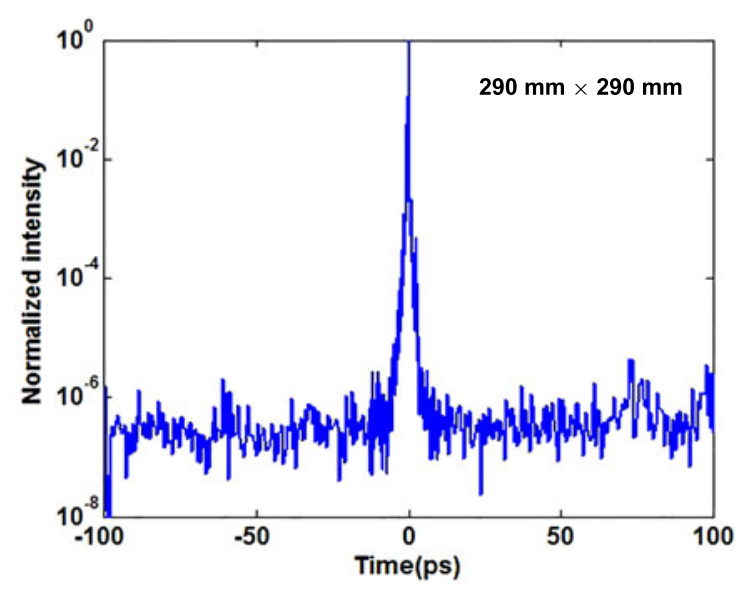

Figure 15. Profile measured by a third-order cross-correlator with the whole beam diameter.

identified as a source of asymmetrical pedestal around amplified pulses. According to Ref. [37], the effect of the scattering in grating based stretchers on the contrast is in the $15 \mathrm{ps}$ range and from $10^{-8}$ to $10^{-5}$ amplitude. The contrast of Figure 15 is only $10^{-6}$ in the 100 ps range, so the asymmetrical pedestal owing to the scattering in the grating based stretcher is covered up. The temporal pedestal before $20 \mathrm{ps}$, ahead of the main pulse, was mainly caused by the parametric fluorescence from OPCPA. The leading edge of the main pulse that has dimensions of few picoseconds was influenced by the residual high-order dispersion and systemwide spatio-temporal couplings among the spatial filters, compressor and focusing optics ${ }^{[38,39]}$. As mentioned above, in SG-II 5PW system, the spatial filters can filter out the high spatial frequency noise of the beam and act as beam expanders; they can improve the near-field beam quality and avoid laser-induced damages to the optical elements in the laser system. According to the long-distance image-relaying requirement of the practical setup, the multiple-stage lensbased spatial filters were designed using the parameters listed in Table $3^{[39]}$. The incident signal beam is expanded from a 2.5 -mm-diameter round shape to a $290 \mathrm{~mm} \times 290 \mathrm{~mm}$ square shape, by five stages of spatial filters (SF1-SF5). The propagation time difference (PTD) is defined by the time delay between the pulse in the center of the beam and that at the edge. The PTD of each spatial filter was calculated according to Ref. [40], which increases with the 


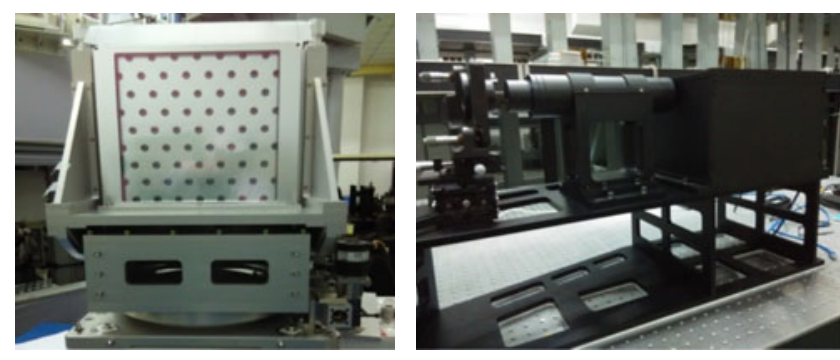

Figure 16. Deformable mirror (left) and Hartmann sensor (right) in AO system.

diameter of the lens-based spatial filters. Numerical analysis shows that the chromatic aberrations and PTD introduced by the lens-based spatial filters spatial-temporally coupled with the compression and focusing can degrade the temporal contrast. This leads to a compressed and focused pulse that has a high noise level and low steepness of the leading edge. Therefore, the chromatic aberrations of SG-II 5PW laser system should be compensated by an additional device or avoided by replacing the lens-based spatial filters with mirror-based spatial filters in order to obtain compressed and focused pulses with a higher temporal contrast.

\subsection{Adaptive optics and focusing}

The AO system in the SG-II 5PW laser facility is utilized to correct both static and dynamic wavefront aberrations and thus to improve the focusing characteristics. The wavefront correction is extremely crucial for large-aperture ultrashort lasers, as the aberrations of the chirped pulses differ not only for spatial regions but also temporally for various wavelengths that cover a wide range. In the SG-II 5PW facility, a deformable mirror (clear aperture: $320 \mathrm{~mm} \times$ $320 \mathrm{~mm}$ ) that consists of 77 piezoelectric ceramic transducer (PZT) actuators fabricated by Institute of Optics and Electronics (IOE, CAS) as well as a Hartmann sensor is located at the master compressor entrance (Figure 16). The wavefront aberrations are measured by the Hartmann sensor using a narrow band-pass filter with the central wavelength of $808 \mathrm{~nm}$ whose bandwidth is $3 \mathrm{~nm}$, corrected by the deformable mirror, and minimized computationally using an accurate numerical algorithm. The defocus and astigmatism are the most significant wavefront aberrations according to the measurement for the whole system.

Using the AO system, the static wavefront aberrations, described by peak to valley (PV) and RMS at $808 \mathrm{~nm}$, respectively, are first improved from $(6.257 \lambda, 0.960 \lambda)$ to $(0.661 \lambda, 0.111 \lambda)$ when all of the OPA are not operated (Figures 17(a) and (b)). Second, before the high energy shot, the shape of the deformable mirror is optimized with an additional data to pre-compensate OPA dynamic aberrations and the inherent aberrations of the master compressor and the off-axis parabolic (OAP) mirror. As shown in Figure 17(c), the dynamic wavefront aberrations are corrected to (1.171 $\lambda, 0.281 \lambda$ ) when both OPA-I and OPA-II are operated. The profiles of the focal spots as well as the encircled energy curves, which are calculated by Fourier transform corresponding to Figures 17(a), (b) and (c), are provided in Figures 17(d), (e) and (f), respectively. It is obtained that the Strehl ratio (StR) of the focal spot is improved from 0.0578 to 0.7836 after the static wavefront correction. However, even if the dynamic wavefront aberrations are precompensated, the StR in Figure 17(f) degrades to 0.4597 because of the real-time jitter of dynamic aberrations. As a result, the focal spot that encompasses $50 \%$ of the energy degrades in diameter from $2.64 \mu \mathrm{m}$ with the static wavefront correction to $5.32 \mu \mathrm{m}$ with the dynamic wavefront pre-compensation. Therefore, another Hartmann sensor is planned to be set after the focusing spot to evaluate the jitter of dynamic aberrations so that the focusing characteristics can be further improved by $\mathrm{AO}$ system in real time.

After the closed-loop correction by the AO system and compressor, the laser beam is focused by an OAP mirror that has a focal length of $800 \mathrm{~mm}$ and $f / 1.95$ into the target chamber as shown in Figure 18. Compared with the focal spot diameter of $\sim 30 \mu \mathrm{m}$ (FWHM) without wavefront correction, the spot quality is greatly improved with the AO system and the spot size is $\sim 10 \mu \mathrm{m}$ (FWHM) (see Figure 19(a)), which is measured by a beam analysis silicon CCD camera (SP620U Spiricon). For this condition, the calculated intensity is up to $10^{21} \mathrm{~W} \cdot \mathrm{cm}^{-2}$ at the focal spot with a compressed pulse of $1.76 \mathrm{PW}$. The SG-II 5PW facility provides 13 shots for high energy physics experiments, and the laser proton acceleration is on average $>7 \mathrm{MeV}$, which is maximized to $>10 \mathrm{MeV}$ for a $10 \mu \mathrm{m}$ copper target. The experimental results when radio-chromic film (RCF) interacted with the accelerated protons indicate that the intensity on the target is up to $1-5 \times 10^{19} \mathrm{~W} \cdot \mathrm{cm}^{-2}$, approximately two orders of magnitude lower than the calculated value of $10^{21} \mathrm{~W} \cdot \mathrm{cm}^{-2[41,42]}$.

The distinction between the calculated intensity and real intensity that is indicated by laser proton acceleration, results from two possible issues. First, the focal spot shown in Figure 19(b), when parametric amplifiers are on operation, is larger than that shown in Figure 19(a). Figure 19(b) imaged online by an X-ray pinhole camera, is a bit saturated and it proves that the focal spot size at the target when OPAs are operating is smaller than $60 \mu \mathrm{m}$ in diameter. We believe that the decrease of the intensity at the target is mainly due to the optical path drift, which is caused by the vacuum chamber deformation. The OAP's focal performance is very sensitive to the drift. In order to analyze the focal characteristics, a numerical model based on a three-dimensional (3D) ray tracing is developed (Figure 20). The simulations show that the focal spot size increases by approximately $1 \mu \mathrm{m}$ when the angular deviation of the incident light and OAP is $5 \mu \mathrm{rad}$ or when there is a $2 \mu \mathrm{m}$ deviation from the focal plane. Therefore, the angular and focal plane deviations should 


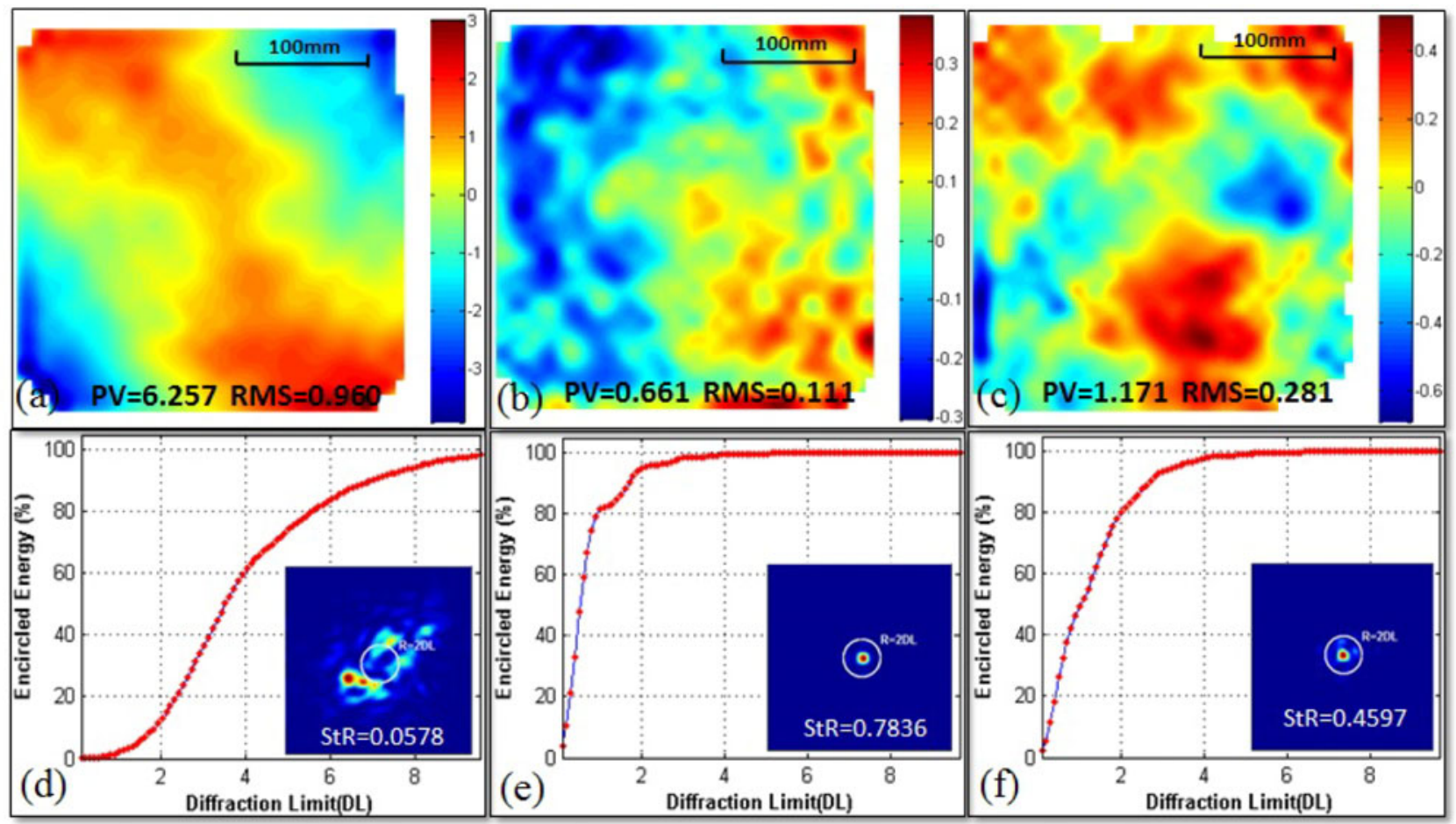

Figure 17. The measured static aberrations (a) before and (b) after correction, and (c) the pre-compensated dynamic aberrations when the amplifiers are on operation at the master compressor entrance; (d), (e) and (f) the calculated encircled energy and the profiles of far-field focal spot, respectively, corresponding to (a), (b) and (c).

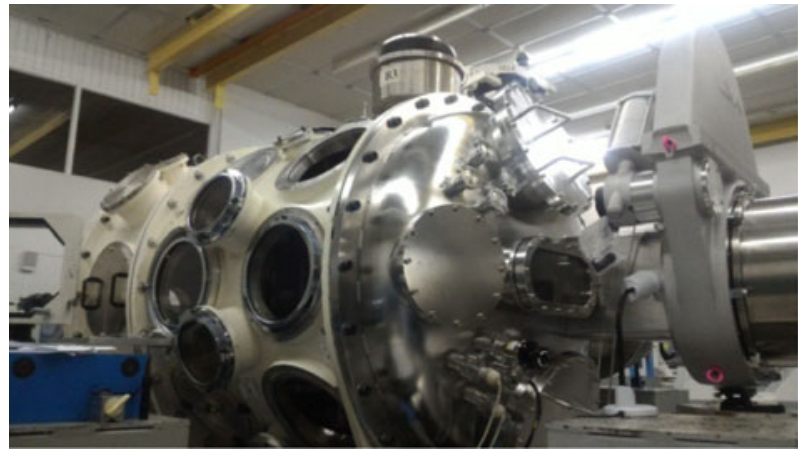

Figure 18. Target chamber.

be less than $25 \mu \mathrm{rad}$ and $10 \mu \mathrm{m}$ in practice. Developing methods to improve the adjustment precision of OAP in the vacuum chamber is a subject of the future work. Second, the contrast at the focal spot should be further improved to values larger than $10^{8}$.

\section{Conclusion}

In this paper, we presented the current performance of the SG-II 5PW facility fully based on OPCPA in the nanosecond domain. The prior two optical parametric amplifiers have realized a chirped-pulse energy of $49.7 \mathrm{~J}$ and a spectrum
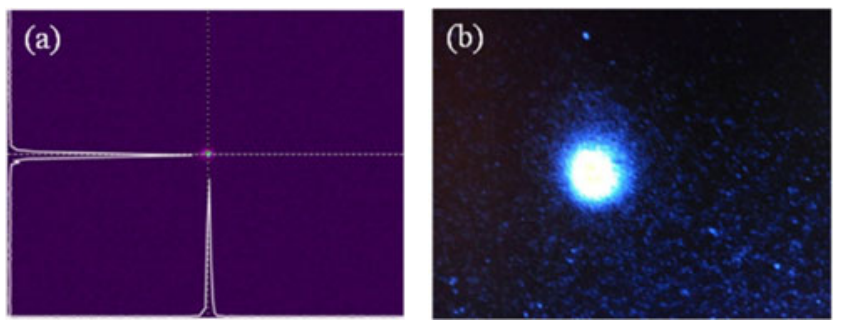

Figure 19. After the AO correction, (a) the focal spot of the unamplified signal pulse imaged by a CCD and (b) that of the high energy pulse imaged by an X-ray pinhole camera.

bandwidth up to $85 \mathrm{~nm}$. In the PW-scale OPA, the pump-tosignal conversion efficiency is $41.9 \%$, which is the highest among all reported values for OPCPA systems. For the first time, we reported duration and contrast measurements with the whole beam diameter for PW-class facilities. It was demonstrated that the peak power of the compressed pulse is higher than $1.76 \mathrm{PW}(37 \mathrm{~J} / 21 \mathrm{fs})$. The static focal spot was $\sim 10 \mu \mathrm{m}$ after the closed-loop correction performed by the AO. The SG-II 5PW facility has succeeded in providing 13 shots for high energy physics experiments. In addition, laser proton acceleration was achieved. This indicates that the effective focused intensity for experiments has exceeded $10^{19} \mathrm{~W} \cdot \mathrm{cm}^{-2}$ and the contrast was not severely degenerated at the focal spot. In the future, both of the focusing 

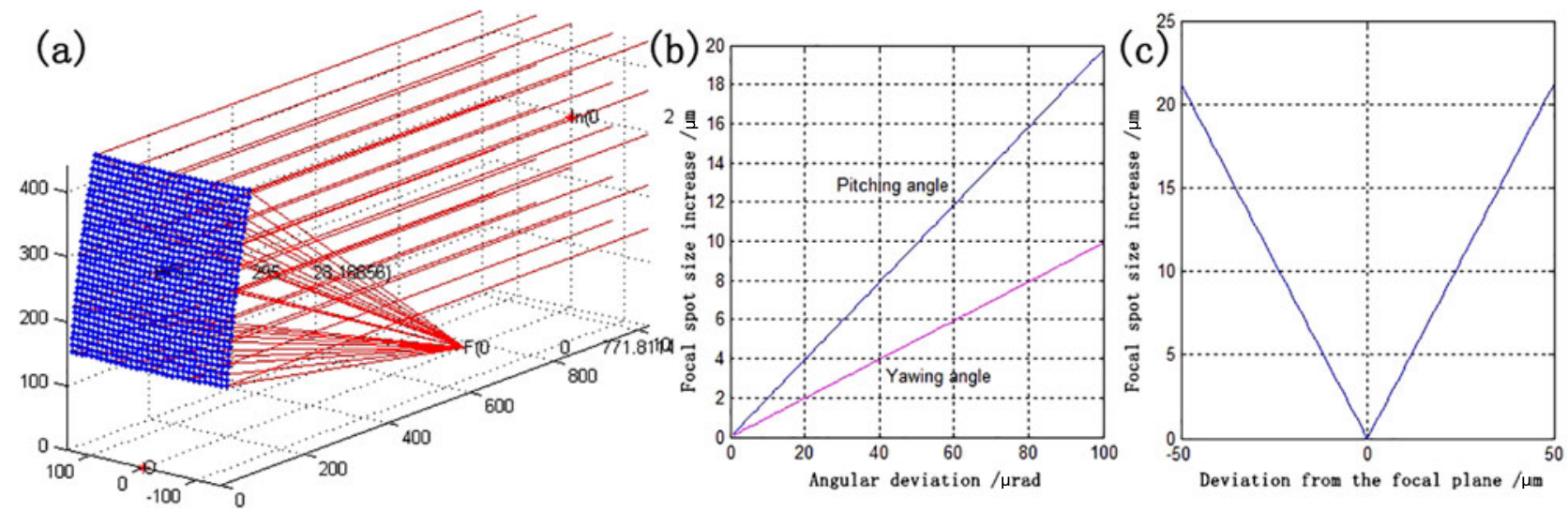

Figure 20. (a) 3D ray tracing of OAP; focal spot size increase (b) as a function of the angular deviation of the incident light and (c) as a function of the deviation from the focal plane.

characteristic and contrast are big issues for the whole system. The OPA-III to realize $5 \mathrm{PW}$ now is under construction. The large-aperture LBO is preferred as the gain media, while DKDP of high level deuteration is an alternative proposal.

\section{Acknowledgements}

M. Sun, J. Kang, Q. Yang, A. Guo and H. Zhu contributed equally to this work. We appreciate all colleagues for their contributions to the development of the SG-II 5PW facility. We thank Xiaochao Wang and Hui Wei for the synchronization system and front end pump laser, D. Liu and P. Zeng for the collimation system and structure cabling, X. Ouyang and S. Tang for the measurement system, Z. Liu, Z. Zhang, K. Gu and J. Miao for the SG-II facility operation, $\mathrm{X}$. Jiang and D. Liu for the SHG and Z. Yang for the discussions about AO. This work was partially supported by the National Natural Science Foundation of China (NSFC) (Nos. 11304332, 11704392, and 61705245) and the Key Projects of International Cooperation in Chinese Academy of Sciences.

\section{References}

1. C. Danson, D. Hillier, N. Hopps, and D. Neely, High Power Laser Sci. Eng. 3, e3 (2015).

2. G. Mourou and T. Tajima, Science 331, 41 (2011).

3. N. Blanchot, G. Béhar, J. C. Chapuis, C. Chappuis, S. Chardavoine, J.F. Charrier, H. Coïc, C. Damiens-Dupont, J. Duthu, P. Garcia, J. P. Goossens, F. Granet, C. Grosset-Grange, P. Guerin, B. Hebrard, L. Hilsz, L. Lamaignere, T. Lacombe, E. Lavastre, T. Longhi, J. Luce, F. Macias, M. Mangeant, E. Mazataud, B. Minou, T. Morgaint, S. Noailles, J. Neauport, P. Patelli, E. Perrot-Minnot, C. Present, B. Remy, C. Rouyer, N. Santacreu, M. Sozet, D. Valla, and F. Laniesse, Opt. Express 25, 16957 (2017).

4. X. Zeng, K. Zhou, Y. Zuo, Q. Zhu, J. Su, X. Wang, X. Wang, X. Huang, X. Jiang, D. Jiang, Y.i Guo, N. Xie, S. Zhou, Z. Wu, J. Mu, H. Peng, and F. Jing, Opt. Lett. 42, 2014 (2017).
5. Z. Gan, L. Yu, S. Li, C. Wang, X. Liang, Y. Liu, W. Li, Z. Guo, Z. Fan, X. Yuan, L. Xu, Z. Liu, Y. Xu, J. Lu, H. Lu, D. Yin, Y. Leng, R. Li, and Z. Xu, Opt. Express 25, 5169 (2017).

6. J. H. Sung, H. W. Lee, J. Y. Yoo, J. W. Yoon, C. W. Lee, J. M. Yang, Y. J. Son, Y. H. Jang, S. K. Lee, and C. H. Nam, Opt. Lett. 42, 2058 (2017).

7. ELI Beamlines, https://www.eli-beams.eu/en/media/news/ livermore-meets-key-milestone-delivery-worlds-high/ (2017).

8. F. Batysta, R. Antipenkov, J. Novák, J. T. Green, J. A. Naylon, J. Horáček, M. Horáček, Z. Hubka, R. Boge, T. Mazanec, B. Himmel, P. Bakule, and B. Rus, Opt. Express 24, 17843 (2016).

9. R. Budriūnas, T. Stanislauskas, J. Adamonis, A. Aleknavičius, G. Veitas, D. Gadonas, S. Balickas, A. Michailovas, and A. Varanavičius, Opt. Express 25, 5797 (2017).

10. J. Moses, C. Manzoni, S. Huang, G. Cerullo, and F. X. Kärtner, Opt. Express 17, 5540 (2009).

11. The Exawatt Center for Extreme Light Studies (XCELS), http://www.xcels.iapras.ru/index.html.

12. A. Lyachev, I. O. Musgrave, Y. Tang, C. Hernandez-Gomez, I. N. Ross, M. Galimberti, O. V. Chekhlov, and J. Collier, Opt. Express 19, 15824 (2011).

13. E. W. Gaul, M. Martinez, J. Blakeney, A. Jochmann, M. Ringuette, D. Hammond, T. Borger, R. Escamilla, S. Douglas, W. Henderson, G. Dyer, A. Erlandson, R. Cross, J. Caird, C. Ebbers, and T. Ditmire, Appl. Opt. 49, 1676 (2010).

14. J. G. Ma, J. Wang, P. Yuan, G. Q. Xie, K. N. Xiong, Y. F. Tu, X. N. Tu, E. W. Shi, Y. Q. Zheng, and L. J. Qian, Optica 2, 1006 (2015).

15. L. J. Waxer, D. N. Maywar, J. H. Kelly, T. J. Kessler, B. E. Kruschwitz, S. J. Loucks, R. L. McCrory, D. D. Meyerhofer, S. F. B. Morse, C. Stoeckl, and J. D. Zuegel, Opt. Photon. News 16, 30 (2005).

16. C. A. Haynam, P. J. Wegner, J. M. Auerbach, M. W. Bowers, S. N. Dixit, G. V. Erbert, G. M. Heestand, M. A. Henesian, M. R. Hermann, K. S. Jancaitis, K. R. Manes, C. D. Marshall, N. C. Mehta, J. Menapace, E. Moses, J. R. Murray, M. C. Nostrand, C. D. Orth, R. Patterson, R. A. Sacks, M. J. Shaw, M. Spaeth, S. B. Sutton, W. H. Williams, C. C. Widmayer, R. K. White, S. T. Yang, and B. M. Van Wonterghem, Appl. Opt. 46, 3276 (2007).

17. J. Y. Zhong, Y. T. Li, X. G. Wang, J. Q. Wang, Q. L. Dong, C. J. Xiao, S. J. Wang, X. Liu, L. Zhang, L. An, F. L. Wang, J. Q. Zhu, Y. A. Gu, X. T. He, G. Zhao, and J. Zhang, Nat. Phys. 6, 984 (2010). 
18. X. Liu, Y. T. Li, Y. Zhang, J. Y. Zhong, W. D. Zheng, Q. L. Dong, M. Chen, G. Zhao, Y. Sakawa, T. Morita, Y. Kuramitsu, T. N. Kato, L. M. Chen, X. Lu, J. L. Ma, W. M. Wang, Z. M. Sheng, H. Takabe, Y.-J. Rhee, Y. K. Ding, S. E. Jiang, S. Y. Liu, J. Q. Zhu, and J. Zhang, New J. Phys. 13, 093001 (2011).

19. Y. Gu, F. Zhang, L. Shan, B. Bi, J. Chen, L. Wei, J. Li, Z. Song, Z. Liu, Z. Yang, M. Yu, B. Cui, Y. Zhang, H. Liu, D. Liu, W. Wang, Z. Dai, Y. Yang, L. Yang, F. Zhang, X. Wu, K. Du, W. Zhou, L. Cao, B. Zhang, J. Wu, G. Ren, H. Cai, S. Wu, L. Cao, H. Zhang, C. Zhou, and X. He, High Power Laser Part. Beams 27, 110101 (2015).

20. J. Zhang, D. Liu, B. Zhu, S. Tang, and Y. Gao, Opt. Eng. 55, 036108 (2016).

21. Y. H. Wang, X. Pan, X. C. Li, and Z. Q. Lin, Chin. Phys. Lett. 26, 024211 (2009).

22. V. Bagnoud, I. A. Begishev, M. J. Guardalben, J. Puth, and J. D. Zuegel, Opt. Lett. 30, 1843 (2005).

23. B. Zhao, Y. Jiang, K. Sueda, N. Miyanaga, and T. Kobayashi, Opt. Express 16, 18863 (2008).

24. E. B. Treacy, IEEE J. Quant. Electron. 5, 454 (1969).

25. D. Huang, W. Fan, and Z. Lin, Chin. J. Lasers 38, 0502008 (2011).

26. J. Liang, R. N. Kohn, Jr., M. F. Becker, and D. J. Heinzen, Appl. Opt. 49, 1323 (2010).

27. L. Xu, L. Yu, X. Liang, Y. Chu, Z. Hu, L. Ma, Y. Xu, C. Wang, X. Lu, H. Lu, Y. Yue, Y. Zhao, F. Fan, H. Tu, Y. Leng, R. Li, and Z. Xu, Opt. Lett. 38, 4837 (2013).

28. F. Zhang, Y. Wang, M. Sun, Q. Bi, X. Xie, and Z. Lin, Chin. Opt. Lett. 8, 217 (2010).

29. Z. Dongfeng, W. Li, and L. Zunqi, Chin. J. Lasers 38, 0702001 (2011).
30. X. Liang, M. Sun, J. Kang, J. Zhou, X. Xie, J. Zhu, and Z. Lin, in Conference on Lasers and Electro-Optics, OSA Technical Digest (Optical Society of America, 2017), paper STu1O.4.

31. M. Sun, Z. Cui, J. Kang, Y. Zhang, J. Zhang, Y. Cui, X. Xie, C. Liu, D. Liu, J. Zhu, and Z. Lin, Proc. SPIE 9621, 96210R (2015).

32. F. Salin, P. Georges, G. Roger, and A. Brun, Appl. Opt. 26, 4528 (1987).

33. D. N. Papadopoulos, J. P. Zou, C. Le Blanc, G. Cheriaux, P. Georges, F. Druon, G. Mennerat, P. Ramirez, L. Martin, A. Freneaux, A. Beluze, N. Lebas, P. Monot, F. Mathieu, and P. Audebert, High Power Laser Sci. Eng. 4, e34 (2016).

34. V. Bagnoud and F. Wagner, High Power Laser Sci. Eng. 4, e39 (2016).

35. E. J. Divall and I. N. Ross, Opt. Lett. 29, 2273 (2004).

36. Y. Chu, Z. Gan, X. Liang, L. Yu, X. Lu, C. Wang, X. Wang, L. Xu, H. Lu, D. Yin, Y. Leng, R. Li, and Z. Xu, Opt. Lett. 40, 5011 (2015).

37. C. Hooker, Y. X. Tang, O. Chekhlov, J. Collier, E. Divall, K. Ertel, S. Hawkes, B. Parry, and P. P. Rajeev, Opt. Express 19, 2193 (2011).

38. P. Zhu, X. Xie, X. Ouyang, and J. Zhu, High Power Laser Sci. Eng. 2, e42 (2014).

39. P. Zhu, X. Xie, and J. Zhu, Acta Opt. Sin. 37, 0914005 (2017).

40. Z. Bor, J. Modern Opt. 35, 1907 (1988).

41. S. Kar, H. Ahmed, R. Prasad, M. Cerchez, S. Brauckmann, B. Aurand, G. Cantono, P. Hadjisolomou, C. L. S. Lewis, A. Macchi, G. Nersisyan, A. P. L. Robinson, A. M. Schroer, M. Swantusch, M. Zepf, O. Willi, and M. Borghesi, Nat. Commun. 7, 10792 (2016).

42. A. Macchi, M. Borghesi, and M. Passoni, Rev. Modern Phys. 85, 751 (2013). 